\title{
Comparative Study on the Status of Glycation Precursors, Advanced Glycation End Products, and Cell Viability Under Effects of Kaempferol, Myricetin, and Azaleatin in HGC-27 Cell Line
}

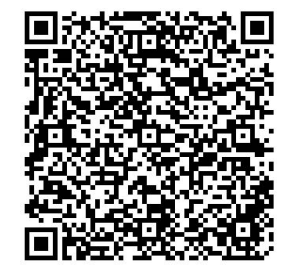

\author{
Fargol Mashhadi Akbar Boojar ${ }^{*}$, Sepideh Golmohamad ${ }^{2}$, Golnaz Tafreshi ${ }^{3}$
}

Glycation as an endogenous process may alter the structure and biological functions of macromolecules, thus playing an important role in cell growth retardation. This study was conducted to evaluate the levels of glycation precursors, advanced glycation end products, and cell viability under effects of kaempferol, myricetin, and azaleatin in the HGC-27 cell line. Results showed that each compound had significant inhibitory effect on cell growth at concentrations of $20 \mu \mathrm{mol}$ and higher, in which kaempferol, myricetin and azaleatin were more effective respectively. Moreover, we had markedly elevated pentosidine content of cells treated with kaempferol, azaleatin and then myricetin in comparison with the control. Kaempferol, myricetin, and azaleatin were more effective, respectively, when 3-deoxyglucoson was increased in a dose-dependent manner Azaleatin caused significantly increased methylglyoxal content, reaching approximately 3.3 folds higher than the control. However, this parameter varied slightly for myricetin and kaempferol-treated cells for all treatment concentrations. Accordingly, the chemopreventive properties of our flavonoides may be attributed to increasing in advanced glycation end products and glycation precursors within treated cells. Moreover, the structural characteristics of these compounds may contribute to their different anticancer activities in this study.

\section{INTRODUCTION}

Glycation, a non-enzymatic glycosylation by glucose and other saccharide derivatives, is a slow endogenous process in living cells under normal physiological conditions (Miyata et al., 1999; Paul et al., 1999). In this process, carbonyl groups of glucose and glucoaldehydes interact with protein amino groups to form a short-life Schiff base which converts rapidly to more stable heterogeneous adducts known as advanced glycation end products (AGEs; Ulrich and Cerami, 2001; Pon Velayutham et al., 2007). The process rises in abnormal conditions such as hyperglycemia, stress, and aging circumstances, leading to lipid and protein adducts that change their structure and biological functions (Lee and Cerami, 1992; Wells-Knecht et al., 1995; Desai and Wu, 2007). Formation of such modified and denatured proteins are closely related to mechanisms of syndrome complications, including diabetes, arterioscle-

\footnotetext{
${ }^{1}$ Faculty of Dentistry, University of Golestan Medical Science, Gorgan, Iran.

${ }^{2}$ Kherad Education Complex, Velenjak Ave, Tehran, Iran.

${ }^{3}$ Faculty of Biological Science, Kharazmi University, No: 43, Shahid Mofateh Ave, P.O. Box: 15719-14911, Tehran, Iran.
}

\footnotetext{
*To whom correspondence should be addressed: mboojar@yahoo.com
}

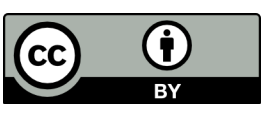

Except where otherwise noted, this work is licensed under https://creativecommons.org/licenses/by/4.0

doi:10.22186/jyi.36.1.5-10 rosis, and Alzheimer's Disease (Hartog et al., 2007; Reddy and Obrenovich, 2002). However, in response to increased glycation, some of the accumulated glycation adducts may be omitted by enzymatic repair mechanisms while others are degraded by proteases (Vander and Hunsaker, 2003; Nemet et al., 2006). The major contributing molecules with different potentials to form AGEs are 3-deoxyglucoson, glyoxal, pentosidine, and methylglyoxal.

3-Deoxyglucosone (3-DG) is a highly reactive dicarboxyl sugar and a precursor for AGE generation by cells, particularly when excessive glucose is taken up or when a person is diabetic. In addition, it can damage some antioxidant enzymes such as glutathione reductase, which is inactivated by excess 3-deoxyglucosone (Tauer et al., 2001; Schalwijk et al., 1999). On the other hand, pentosidine is a fluorescent molecule and represents an adequate and sensitive marker for all AGEs within cells. It is an imidazole [4,5b] pyridinum ring formed by cross linking between lysine and arginine residues (Dyer et al., 1991; Spacek and Adam, 2002).

The elevation of pentosidine is associated with ageing and related complications, including cartilage stiffness and damage that causes physical disability (Senolt et al., 2005; Verzijl et al., 2002).

Glyoxal may be formed via autoxidation and spontaneous degradation of glucose by retro-aldol condensation under physiological conditions (Paul et al., 1999). The methylated form of this compound, methylglyoxal, can be produced by fragmentation of 3-deoxyglucosone and is also a byproduct of glycolysis and amino acid catabolism (Frank et al., 1996).

Current knowledge of glycation indicates that it may be an 
important therapeutic target for improvement of hyperglycemia and diabetes complications, particularly by plant-extracted compounds (Kazeem et al., 2012). Flavonoids are a large family of bioactive secondary metabolites and constitute one of the most ubiquitous groups of all plant phenols. They have many positive effects on diabetes, offering an attractive alternative to related chemical drugs (Russo, 2007). Flavonoids with a ketone group are subdivided into different subgroups including flavonols, in which kaempferol and myricetin are the most studied. They differ in the degree of unsaturation and oxidation of their $\mathrm{C}$ ring (Panche et al., 2016). Kaempferol (KPF) and azaleatin, small polyphenolic molecules found in a number of plant-dietary sources, have been reported to have multiple xenobiotic effects. This includes improving glucose tolerance, diabetes, and cardiovascular disorders (Manach et al., 2004).

Increasing AGEs by bioactive compounds and determination of their mechanism action, particularly in cancerous cell lines attracted great attention in recent years for cancer prevention (Chethan et al., 2016). On the other hand, human gastric cancer cell line, specified as (HGC-27) derived from the metastatic lymph node of gastric cancer, is considered as a biological model for invitro studies (Mireia et al., 2016; Jixia et al., 2016). Based on our literature review, the precise mechanism underlying the biological effects of our three compounds on AGEs and the glycation process in the HGC-27 cell line has not been studied until now. Accordingly, the aim of our study was to evaluate the main glycation precursors and AGEs levels within cells and cell viability in response to treatment with kaempferol, myricetin, and azaleatin.

Due to structure-function relationships, we hypothesized that these compounds have different potentials and abilities to elevate advanced glycation end products within our cancer cell line, possibly inhibiting cell proliferation.

\section{MATERIALS AND METHODS}

\section{Cell viability}

The effects of drugs on the growth of cells were assessed with a trypan blue dye exclusion assay. Briefly, HGC-27 cells, immortalised human-stomach adenocarcinoma cells, were seeded onto 24 -well plates $\left(50 \times 10^{3}\right.$ cells/well $)$ and grown overnight. The cells were then treated with different concentrations $(0,50,100,150$, 200 and $250 \mu \mathrm{M}$ ) of each compound. Control and treated cells were then incubated for $48 \mathrm{hr}$. After the incubation period, cells were washed twice with phosphate-buffered saline solution and incubated with 3-(4,5-dimethylthiazol-2-yl)-2,5-diphenyl tetrazolium bromide (MTT) solution at a final concentration of $0.5 \mathrm{mg}$ / $\mathrm{mL}$ for $3 \mathrm{hr}$ and then lysed in dimethylsulfoxide. Optical density was measured at $540 \mathrm{~nm}$, and the background absorbance measured at $660 \mathrm{~nm}$ was subtracted. All samples were assayed at least in three independent experiments in duplicate, and the mean value for each experiment was calculated. The results are given as mean \pm S.E.M. and are expressed as percentage of control, which was considered to be $100 \%$ (Negrão, et al., 2010).

Methylglyoxal and glyoxal assay
We used 4-methoxy-o-phenylenediamine (4MPD) as a derivatizing agent, and acetonitrile was added to treated cells for matrix precipitation. An aliquot of treated HGC-27 cell lysate extract or calibration standard solution $(200 \mu \mathrm{L})$ was mixed with $20 \mu \mathrm{L}$ of internal standard and $200 \mu \mathrm{L}$ of acetonitrile for matrix precipitation and then sample was centrifuged (10,000 xg, $5 \mathrm{~min})$. For derivatization, $150 \mu \mathrm{L}$ of supernatant was mixed with $240 \mu \mathrm{L}$ of water and $60 \mu \mathrm{L}$ of phosphate buffer $(500 \mathrm{mM}, \mathrm{pH} 7.4), 10 \mu \mathrm{L}$ of 4MPD $(20 \mathrm{mg} / \mathrm{mL})$ was added as a derivatizing reagent. The mixture was incubated at $40 \mathrm{oC}$ for $4 \mathrm{hr}$. Finally, the sample was acidified with $10 \mu \mathrm{L}$ of $\mathrm{HCl}(3 \mathrm{M})$, diluted with $200 \mu \mathrm{L}$ of acetonitrile, saturated with sodium chloride and centrifuged (10,000 xg, $5 \mathrm{~min})$. $75 \mu \mathrm{L}$ of acetonitrile layer was mixed with $150 \mu \mathrm{L}$ of mobile phases with 5\% 2-mercaptoethanol. Mobile phase consisted of 1:1 of water $(\mathrm{A})$ and a mixture of $0.8 \%$ acetic acid with $0.6 \%$ EDTA $(\mathrm{C})$. The injection volume to the high performance liquid chromatography fluorimetric detector (HPLC-FLD) system was $20 \mu \mathrm{L}$. Separation of methylglyoxal and glyoxal was accomplished using three mobile phases (A [water], B [acetonitrile], and C [0.8\% acetic acid and $0.6 \%$ TEA], $(\mathrm{pH} 4.3)$ and the following gradient elution: 0 to $1 \mathrm{~min}, 70 \% \mathrm{~A}, 20 \% \mathrm{~B}, 10 \% \mathrm{C}$; 1 to $6 \mathrm{~min}, 50 \% \mathrm{~A}, 40 \% \mathrm{~B}, 10 \%$ $\mathrm{C} ; 6$ to $8 \mathrm{~min}, 20 \% \mathrm{~A}, 70 \% \mathrm{~B}, 10 \% \mathrm{C} ; 8$ to $10 \mathrm{~min}, 10 \% \mathrm{~A}, 80 \%$ $\mathrm{B}, 10 \% \mathrm{C} ; 10$ to $10.2 \mathrm{~min}, 70 \% \mathrm{~A}, 20 \% \mathrm{~B}, 10 \% \mathrm{C} ; 10.2$ to $12 \mathrm{~min}$, $70 \% \mathrm{~A}, 20 \% \mathrm{~B}, 10 \% \mathrm{C}$; with a total flow rate of $0.5 \mathrm{~mL} / \mathrm{min}$. For fluorimetric detection, excitation and emission wavelengths were set at 344 and $420 \mathrm{~nm}$, respectively (Ojeda et al., 2014).

\section{3-Deoxyglucosone assay}

The level of 3-DG was measured by HPLC method. Briefly, 300 $\mu \mathrm{L}$ of cell extract or 3DG standard was added to $30 \mu \mathrm{L}$ of $60 \%$ perchloric acid solution and centrifuged at 3,000 rpm for $5 \mathrm{~min}$. The supernatant was neutralized by disodium carbonate and then added to $0.1 \%$ 2, 3-diaminonaphthalene and $0.005 \%$ 2, 3-pentanedione. The reaction was conducted at $4 \mathrm{oC}$ overnight. The reaction mixture was extracted using ethyl acetate, followed by evaporation until dry. The dried extract was reconstituted with 50\% methanol and was later used for injection in reverse phase using a TSK-GEL ODS-80TM column $(4.6 \times 250 \mathrm{~mm}$, particle size $5 \mu \mathrm{m})$ of HPLC system. HPLC assay applied linear gradient system of $50 \mathrm{mmol} / \mathrm{L}$ phosphate-methanol-acetonitrile solvent on at $268 \mathrm{~nm}$ detection (Yoshikazu et al., 2010).

\section{Pentosidine determination}

Pentosidine was quantified by the method of Dyer et al. (1991). Samples were dialyzed against phosphate buffer at a ratio of 1000:1 overnight, changing the dialysate every $8 \mathrm{hr}$. The remaining solution was concentrated by evaporator, then hydrolyzed by adding $6 \mathrm{M} \mathrm{HCL}$ for $12 \mathrm{hr}$ at $110 \mathrm{oC}$. Hydrochloric acid in solution was evaporated again by evaporator and then diluted with water, neutralized by the addition of $\mathrm{NaOH}$. After filtration, it was used for injection into a $\mathrm{C} 18$ reversed phase separation column (Nova-pak, $150 \times 3 \mathrm{~mm}$, particle size $5 \mu \mathrm{m}$ ) in HPLC system. Elution solution was $0.1 \%$ trifluoroacetic acid (solvent $\mathrm{A}$ ) and $100 \%$ acetonitrile (solvent $\mathrm{B}$ ) with $0.8 \mathrm{~mL} / \mathrm{min}$ flow rate. A step gradient was formed by adjusting the volumes of solutions $\mathrm{A}$ and $\mathrm{B}$ at the 


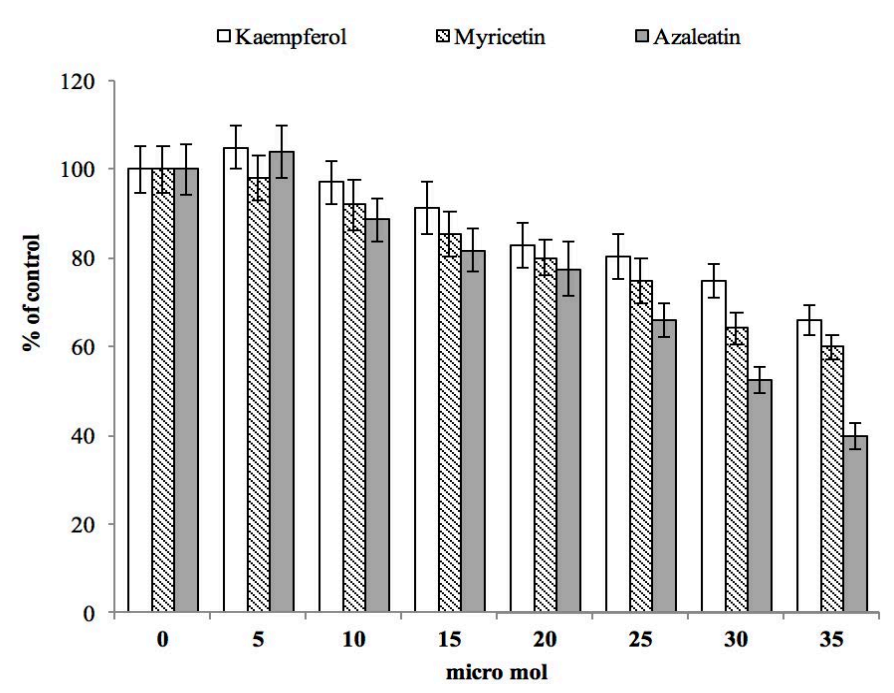

Figure 1. The effect of cell treatment with three different compounds on cell viability as evaluated by MTT assay.

times indicated: from 0 to $87 \%$ A for $85 \mathrm{~min}$, from $87 \%$ to $100 \%$ A for $20 \mathrm{~min}$ and $100 \%$ for $15 \mathrm{~min}$. The pentosidine standard was detected by fluorescence at excitation wave length $325 \mathrm{~nm} /$ emission wavelength $385 \mathrm{~nm}$ and eluted at approximately $67 \mathrm{~min}$.

\section{Statistical analysis}

Each test was repeated three times and the comparison of average data between the control and the different treatments was obtained using SPSS software (ANOVA test).

\section{RESULTS}

Cell viability in response to treatment with each compound is exhibited in Figure 1. All studied compounds had a significant inhibitory effect on cell growth at concentrations of $20 \mu \mathrm{mol}$ and higher compared to the control, with kaempferol, myricetin, and azaleatin more effective respectively. However, this restriction effect started at $10 \mu \mathrm{mol}$ for azaleatin and finally reached about $40 \%$ of the control.

For evaluation of AGEs, we assayed pentosidine levels in cells that were exposed to different concentrations of our compounds (Figure 2). Data revealed slight variations in this parameter for kaempferol and azaleatin from 0 to $20 \mu \mathrm{mol}$, but higher concentrations caused significant elevation in comparison to the control. The slope of the variation curve was greater for myricetin with respect to other compounds. Accordingly, the pattern in pentosidine was markedly increasing for kaempferol, azaleatin and then for myricetin (kaempferol < azaleatin < myricetin). Maximum level of pentosidine $(92 \mu \mathrm{mol})$ was observed following treatment with $35 \mu \mathrm{mol}$ of myricetin.

Variations in 3-DG within cells in exposure to our flavonoides are shown in Figure 3. A dose-dependent increase was observed for all compounds, with kaempferol, myricetin, and azaleatin being more effective respectively. All three compounds caused a significant increase in this parameter at concentrations of $15 \mu \mathrm{mol}$ and

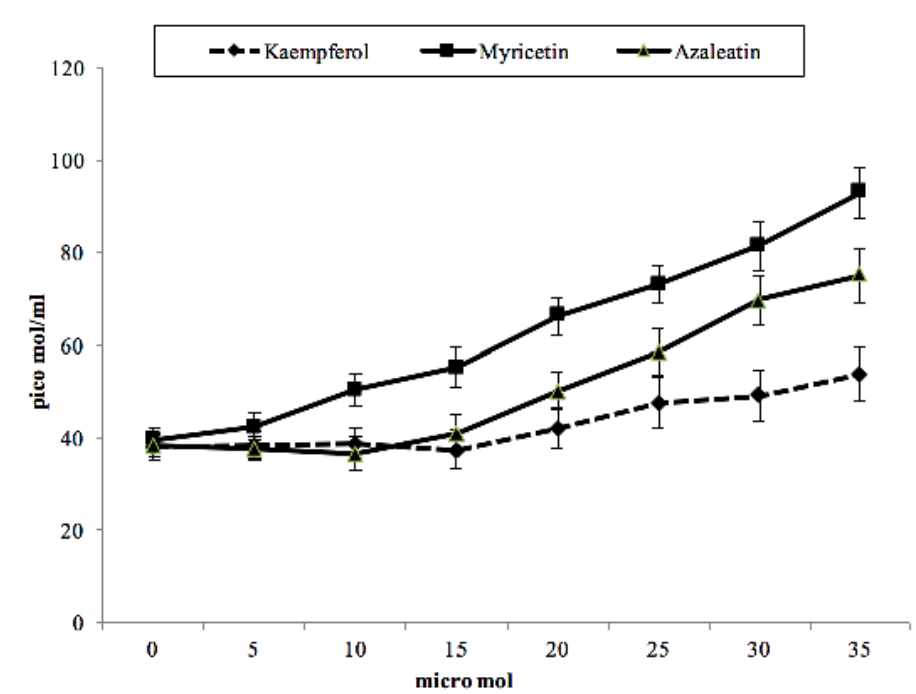

Figure 2. The effect of cell treatment with different concentrations of three compounds on pentosidine concentration after $24 \mathrm{hr}$ incubation.

higher in comparison to the control. In addition, treatment with the maximum concentration of azaleatin and myricetin caused 3-deoxyglucoson to reach 2.5 and 2.1 times the control respectively. Table 1 shows methylglyoxal content of treated and control cells. Azaleatin caused a significant elevation of this value at $5 \mu \mathrm{mol}$ and above, and it reached about 3.3 times higher than the control. This increasing effect was also considerable and significant as compared to myricetin and kaempferol for all treatment concentrations. On the other hand, myricetin and kaempferol showed moderate increases that were only significant at $30 \mu \mathrm{mol}$ and above, with respect to control.

\section{DISCUSSION}

Flavonoids belong to a class of secondary plant metabolites with favourable biochemical effects. They include several substances with various bioactivities and pharmacological applications, particularly in combination therapy. One of such therapeutic aspects is their retardation capability on cancerous cells and there is considerable interest knowing their mechanism of action (BenaventeGarcia et al., 2007). On the other hand, formation of high amounts of active glycation precursors and AGEs in cancerous cells is a strategy for their growth retardation and viability inhibition. Accordingly, we tested HCG-27 to evaluate their response to treatment with three flavonoles with various structures including kaempferol, myricetin, and azaleatin. An MTT assay revealed that our compounds had cytotoxic effects at different intensities when treated with concentrations of $20 \mu \mathrm{mol}$ and higher. Based on the level of anti-cancerous potential in our study, azaleatin could be grouped as highly toxic, myricetin as moderately toxic and kaempferol as slightly toxic.

Our finding is in accordance with other reports which show that using crude-extract of flavonoids prevent the initiation of various cancer cell lines and other cell cycle stages (Joeng et al., 2009). In accordance with our obtained data about kaempferol cy- 


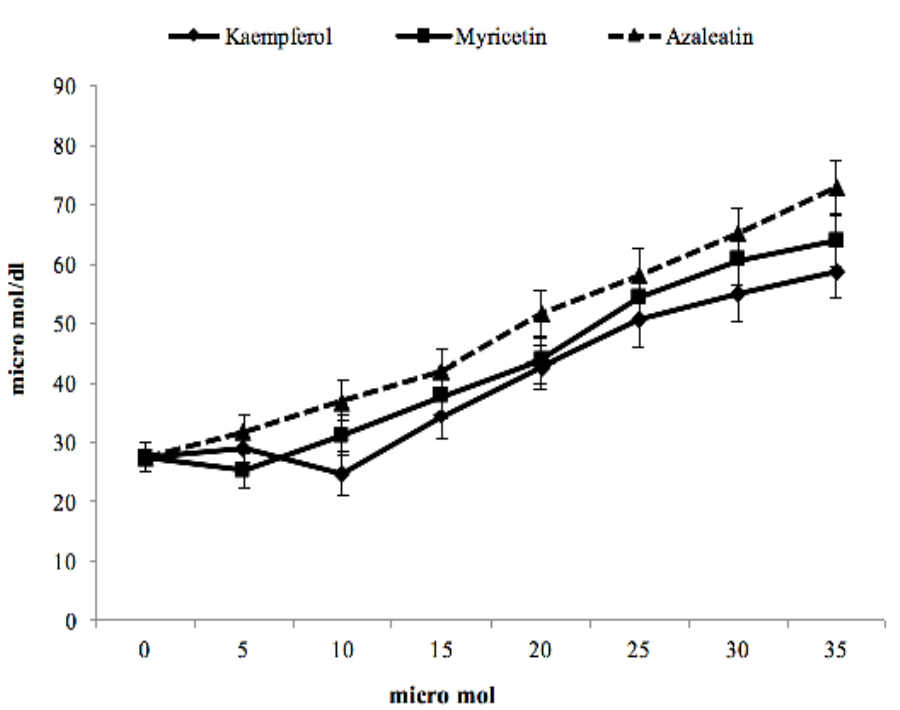

Figure 3. The effect of cell treatment with different concentrations of three compounds on 3-deoxyglucosone after $24 \mathrm{hr}$ incubation.

totoxicity, an investigation in detail mechanism reported by Nguyen et al. (2003), showed that treatment of A549 lung cancer cell line resulted in a dose-dependent reduction in cell viability. On the other hand, investigation by Phillips et al. (2011), confirmed the myricetin induced cell death in metastatic and primary pancreatic cancer cell lines as evaluated by MTT assay. In addition, another study showed that myricetin is a natural inhibitor of neoplastic cell transformation and tumor development (Ki won et al., 2007). High biochemical effectiveness of myricetin in this study is in agreement to another report which demonstrated that myricetin has a unique chemical structure with high anticancer and antioxidant activities (Lei et al., 2014).

Moreover, there are some reports on anticancer effects of quercetin derivatives and related bioflavonoids including azaleatin (Di Carlo et al., 1999). Flavonoids may induce cellular cytotoxicity through a generalized signalling pathway in which their chemical structure plays important roles. Flavonoids are characterized by a diphenylpropane carbon skeleton of C6-C3-C6, where two benzene rings are linked. Differences in the number and arrangement of the hydroxyl groups and unsaturation bound of the rings leads to different cytotoxicity effects (Yao et al., 2011; Yadegarynia et al., 2012).

Recently, extensive studies have been conducted to clarify the biochemical effects responsible for the chemopreventive properties of several flavonoides. Many studies have revealed that there is a causal relationship between glycation elevation and induction of cytotoxicity, even in cancer cells (El-Osta et al., 2008). An increase in AGEs and the glycation process can alter the structure of many classes of biomolecules, particularly proteins, DNA and enzymes, leading to their hypofunction and even dysfunction. These processes may potentiate apoptosis that is closely associated with reduction of cell viability. Accordingly, we determined the status of glycation precursors and related parameters known as AGEs.
Pentosidine is a typical compound among AGEs. It is formed at the end of the Milard reaction, in which ribose reacts with amino acids. It forms fluorescent cross-links between the arginine and lysine residues in proteins, consequently compromising their structural integrity. Pentosidine is therefore useful for assessing cumulative damage to proteins (Toshio et al., 1998).

We checked pentosidine levels in cells treated with each of the three compounds. Our study showed that myricetin was the most effective for pentosidine elevation. However, the increasing effect of kaempferol was insignificant and azaleatin had moderate increasing effects.

We also found that the effective concentrations for pentosidine increase were in the same range of concentrations for retardation of cell growth by these compounds in treated cells. Accordingly, we believe that high levels of pentosidine may be involved in cell growth retardation. In the present study, the inhibition effect of high levels of pentosidine on treated cancer cells may be attributed to the induction of apoptosis. It has been shown that in presence of high doses of pentosidine and other AGEs, the receptor for advanced glycation end products (RAGE) are upregulated, by which apoptosis is induced (Mahali et al, 2011). Another aspect of pentosidine cytotoxicity may rise from proteins damaged by this molecule within the cellular matrix, internal and/or external. Cellular matrix proteins play important roles in cell proliferation and survival, and their alterations can lead to apoptosis and cell death (Masahiko and Raymond, 1995; Daley et al., 2008).

High levels of 3-DG, as an AGE precursor, play cytotoxic roles by different mechanisms (Rabbani et al., 2012, and Toshimitsu et al., 1999). 3-DG is a product from spontaneous glucose degradation in an early stage of the Milard reaction and is of particular importance because of its high reactivity and potential to induce the formation of AGEs (Tauer et al., 2001). The formation of this AGE precursor occurs by deprotonation of carbon-2 of glucose, and then re-distribution of the electron density between carbon 2 and carbon 3 leads to formation of 3-DG (Paul et al., 1999).

Our investigation showed an increasing pattern in this parameter in response to exposure to our studied compounds, of which kaempferol, myricetin, and azaleatin were more potent respectively. We concluded that high doses of 3-DG were involved in their cytotoxic properties. In agreement with our findings, Szwergold et al. (1990) confirmed that 3-DG, as a highly reactive sugar, rapidly reacts with protein amino groups to form AGEs including imidazol, pyralin, and carboxymethyl lysine. In this way, 3-DG plays a key role in the modification and cross linking of long lived proteins, making them defective and causing cell growth retardation and cytotoxicity (Dyer et al., 1991).

In addition, 3-DG is responsible for production of intercellular oxidative stress and also inactivates some of the most important antioxidative enzymes subsequently cause elevation in reactive oxygen species (ROS). These reactive species can damage and dysfunction many classes of macromolecules. On the other hand, another studied revealed that 3-DG could induce apoptosis in macrophage derived cell lines (Shinpo et al., 2000). 
Table 1. Methyl glyoxal content $(\mu \mathrm{mol} / \mathrm{mL})$ in extract of cells exposed to three different compounds after $24 \mathrm{hr}$ incubation. Data are expressed as $\%$ of control and are \pm S.D.

\begin{tabular}{ccccccccc}
\hline & \multicolumn{7}{c}{ Concentration $(\mu \mathrm{mol} / \mathbf{m L})$} \\
Compound & $\mathbf{0}$ & $\mathbf{5}$ & $\mathbf{1 0}$ & $\mathbf{1 5}$ & $\mathbf{2 0}$ & $\mathbf{2 5}$ & $\mathbf{3 0}$ \\
\hline Kaempferol & $26.0 \pm 2.1$ & $24.3 \pm 1.6$ & $27.2 \pm 2.4$ & $28.8 \pm 2.4$ & $26.3 \pm 2.1$ & $29.2 \pm 2.2$ & $34.3 \pm 2.7$ & $36.1 \pm 3.0$ \\
\hline Myrcetin & $26.0 \pm 2.1$ & $28.1 \pm 2.4$ & $25.0 \pm 2.2$ & $29.1 \pm 2.2$ & $32.0 \pm 2.5$ & $33.3 \pm 2.6$ & $35.1 \pm 2.9$ & $38.0 \pm 3.2$ \\
Azaleatin & $26.0 \pm 2.1$ & $31.6 \pm 2.0$ & $37.7 \pm 3.1$ & $46.6 \pm 3.8$ & $57.9 \pm 5.0$ & $70.4 \pm 6.1$ & $81.1 \pm 7.1$ & $88.3 \pm 7.7$ \\
\hline
\end{tabular}

It is likely in our study that kaempferol, myricetin, and azaleatin were able to develop cytotoxicity through the key role of 3-DG in oxidative damage, apoptosis, and functional protein cross linking (Toshimitsu, et al., 1999; Jalaluddin, 2015). Apart from 3-DG, methylglyoxal is another AGE precursor that is encountered in macromolecules glycation adducts. Therefore, we investigated this factor in treated cells, and data (Table 1) showed that kaempferol and myricetin were not as effective on this parameter as they were for 3-DG and pentosidine. They caused less increase in methylglyoxal with respect to azaleatin. Azaleatin caused methylglyoxal to reach 3.4 folds of control at final treatment concentration, accordingly methylgloxalis believed to have a considerable role in azaleatin toxicity. We had the highest increasing in methylglyoxal levels among the assayed parameters. In accordance to our findings, Tan et al. (2008) illustrated that methylglyoxal is one of the most prominent reactive sugar aldehydes encountered in cellular damage, by promoting AGE formation. In addition, this compound is considered a relevant biomarker of oxidative degradation of lipids within cells (Shangari and O'Brien, 2004). On this basis, we concluded that our cytotoxicity response to azaleatin could be attributed to methylglyoxal elevation. We observed that the cumulative roles of pentosidine, 3-DG, and methylglyoxal were included in azaleatin's toxicity effect on HGC-27 cells, leading to high potential cytotoxicity of azaleatin with respect to myricetin and kaempferol.

In this study, we checked three individual compounds of the flavonol class, differing in the pattern of substitution of A ring and degree of hydroxylation on B ring that dictate their chemical nature and biological functions (Kelly et al., 2002). Past reports indicate that the presence of free hydroxyl groups, their number and mutual location on the structure of these compounds can alter their antioxidant (Wang, et al., 2006) and anticancer activities (Williams, et al., 2004). In this regard, we can suggest that lack of two $\mathrm{OH}$ groups on the $\mathrm{B}$ ring of kaempferol not only made it less cytotoxic with respect to myricetin and azaleatin, but this also weakens the potency for glycation formation. In agreement with our results, Benavente-Garcia et al. (2007) showed that myricetin, with three adjacent $\mathrm{OH}$ on the $\mathrm{B}$ ring, resulted in a stronger antiproliferative effect with respect to other flavonoides with less $\mathrm{OH}$ groups. In azaleatin, a methylated flavonol, a methyl group is substituted instead of an $\mathrm{OH}$ group on A ring, differing it from myricetin and kaempferol. Recent studies have confirmed that methylated flavonoids show high metabolic stability and cell bioavailability in comparison with the un-methylated forms (Walle, 2007). Accordingly, we conclude that the higher potency of azaleatin in this study could be attributed to this structural property, making it more effective on retardation of cell viability and increase of 3-DG and methylglyoxal with respect to myricetin and kaempferol. Although structure-function relationship has been well established for antioxidant and antiproliferative effects of flavonoides, more studies are needed to clarify the mechanistic details by which structural properties affect the generation of glycation precursors and AGEs.

In conclusion, our study shows that the elevation of glycation precursors and the levels of AGEs can be considered an attractive target for clarifying another aspect of anticancer-promoting mechanism in response to myricetin, kaempferol and azaleatin. An increased number of $\mathrm{OH}$ and substitution of methyl on benzene ring as structural characteristics of these compounds play important role in elevation of glycation parameters, leading to better inhibitory effects on HGC-27 cells viability by kaempferol, myricetin, and azaleatin respectively.

\section{ACKNOWLEDGMENTS}

The author is grateful to the deputy of research of Kharazmi University.

\section{REFERENCES}

Benavente-Garcia O, Castillo J, Alcaraz M, Vicente V, Del Rio JA, Ortuno A. Beneficial action of Citrus flavonoids on multiple cancer-related biological pathways. Current Cancer Drug Targets (2007), 7:8, 795-809.

Daley WP, Peters SB, and Larsen M. Extracellular matrix dynamics in development and regenerative medicine. Journal Cell Science (2008), 121, 255-264.

Desai K, Wu L. Methylglyoxal and advanced glycation end products: new therapeutic horizons? Recent Pat. Cardiovasc. Drug Discovery (2007), 2:2, 89-99.

Di Carlo G, Mascolo N, Izzo AA, Capasso F. Flavonoids: old and new aspects of a class of natural therapeutic drugs. Life Science (1999), 65, 337-353.

Dyer DG, Blackledge JA, Thorpe SR, Baynes JW. Formation of pentosidine during nonenzymatic browning of proteins by glucose. Identification of glucose and other carbohydrates as possible precursors of pentosidine in vivo. Journal Biological Chemistry (1991), 266:18, 11654-60.

El-Osta A, Brasacchio D, Yao D, et al. Transient high glucose causes persistent epigenetic changes and altered gene expression during subsequent normoglycemia. Journal of Experimental Medicine (2008), 205:10, 2409-2417.

Chaplen FWR, Fahl WE, and Cameron DC. Method for Determination of Free Intracellular and Extracellular Methylglyoxal in Animal Cells Grown in Culture. Analytical Biochemistry (1996), 238, 171-178.

Hartog JW, Voors AA, Bakker SJ, Smit AJ and van Veldhuisen DJ. Advanced glycation end-products (AGEs) and heart failure: pathophysiology and clinical implications. European Journal Heart Failure (2007), 9:12, 1146-1155.

Jeong JH, et al. Effects of low dose quercetin: cancer cell-specific inhibition of cell cycle progression. Journal Cell Biochemistry (2009), 106(1), 73-82. 
Kazeem MI, Akanji M, Hafizur A, Rahman M, Choudhary MI. Antiglycation, antioxidant and toxicological potential of polyphenols extracts of alligator pepper, ginger and nutmeg from Nigeria. Asian Pacific Journal of Tropical Biomedicine (2012), 727-732.

Kelly EH, Anthony RT, and Dennis JB. Flavonoid antioxidants: chemistry, metabolism and structure-activity relationships. Journal of Nutritional Biochemistry (2002), 13:10, 572-584.

Lee KW, Kang NJ, Rogozin EA, Kim HG, Cho YY, Bode AM, et al. Myricetin is a novel natural inhibitor of neoplastic cell transformation and MEK1. Carcinogenesis (2007), 28:9, 1918-1927.

Lee AT, Cerami A. Role of glycation in aging. Ann N. Y Academic Science (1992), 663, 63-70.

Mahali SI, Raviprakash N, Raghavendra PB, Manna SK. Advanced glycation end products (AGEs) induce apoptosis via a novel pathway: involvement of $\mathrm{Ca}^{2+}$ mediated by interleukin-8 protein. Journal Biological Chemistry (2011), 286:40, 34903-13.

Manach C, Scalbert A, Morand C, Remesy C, Jimenez L. Polyphenols: food sources and bioavailability. American Journal Clinical Nutrition (2004), 79, 727 747.

Miyata T, Van Ypersele de Strihou C, Kurokawa H, and Baynes JW. Alterations in nonenzymatic biochemistry in uraemia: origin and significance of carbonyl stress in long-term uremic complications. Kidney International (1999), 55 , 389-399.

Negrão R, Costa R, Duarte D, Taveira GT, Mendanha M, Moura L. Angiogenesis and inflammation signaling are targets of beer polyphenols on vascular cells. Journal Cell Biochemistry (2010), 111, 1270-9.

Nemet I, Varga-Defterdarovic L, Turk Z. Methylglyoxal in food and living organisms, Molecular Nutrition Food Research (2006), 50, 1105-1117.

Nguyen TTT, Tran E, Ong CK, Lee SK, Do PT, Huynh TT, Nguyen TH, Lee JJ, et al. Kaempferol-induced growth inhibition and apoptosis in A549 lung cancer cells is mediated by activation of MEK-MAPK. Journal of Cellular Physiology (2003), 197:1, 110-121.

Ojeda AG, Wrobel K, Corrales Escobosa AR, Garay-Sevilla ME, Wrobel K. Highperformance liquid chromatography determination of glyoxal, methylglyoxal, and diacetyl in urine using 4-methoxy-o-phenylenediamine as derivatizing reagent. Analytical Biochemistry (2014), 449, 52-58.

Panche AN, Diwan AD and Chandra SR. Flavonoids: an overview. Journal of Nutritional Science (2016), 5:e47, 1-15.

Paul J, Thornalle AL and Harjit SM. Formation of glyoxal, methylglyoxal and 3-deoxyglucosone in the glycation of proteins by glucose. Biochemical Journal (1993), 344, 109-116.

Pon Velayutham AB, Adikesavan G, Rajendra D, DowlathA, Chandrasekara vimal PK. Protective effect of Withania somnifera (Solanaceae) on collagen glycation and cross-linking. Comparative biochemistry and physiology (2007). Part B, 147, 308-313.

Reddy VP, Obrenovich ME, Atwood CS. Involvement of Millard reactions in Alzheimer disease. Neurotoxins Research (2002), 4, 191-209.

Russo GL. Ins and outs of dietary phytochemicals in cancer chemoprevention. Biochemistry Pharmcology (2007), 74, 533-544.

Schalwijk C, Posthuma N, Ten Brink H, Ter Wee P, Teerlink T. Induction of 1,2-dicarbonyl compounds, intermediates in the formation of advanced glycation endproducts, during heat-sterilization of glucose-based peritoneal dialysis fluids. Perit Dial International (1999), 19, 325-33.

Senolt L, Braun M, Olejárová M, Forejtová S, Gatterová J, Pavelka K. Increased pentosidine, an advanced glycation end product, in serum and synovial fluid from patients with knee osteoarthritis and its relation with cartilage oligomeric matrix protein. Annual Rheumatology Disease (2005), 64:6, 886- 90.

Shangari N, O'Brien PJ. The cytotoxic mechanism of glyoxal involves oxidative stress. Biochemistry Pharmacology (2004), 68, 1433-1442.

Shinpo K, Kikuchi S, Sasaki H, Ogata A, Moriwaka F, Tashiro K. Selective vulnerability of spinal motor neurons to reactive dicarbonyl compounds, intermediate products of glycation, in vitro: implication of inefficient glutathione system in spinal motor neurons. Brain Research (2000), 861:1, 151-9.

Spacek P, Adam M. HPLC method for pentosidine determination in urine, serum and tissues as a marker of glycation and oxidation loading of the organism. Journal Liquid Chromatography Related Technology (2002), 25:12, 1807 -
20

Szwergold BS, Kappler F, Browm TR. Identification of fructose 3-phosphate in the lens of diabetic rats. Science (1990), 247:4941, 451-454.

Tan D, Wang Y, Lo CY, Ho CT. Methylglyoxal: its presence and potential scavengers. Asia Pacific Journal Clinic Nutrition (2008), 17, 261-264.

Tauer A, Knerr T, Niwa T, Schaub TP, Lage C, Passlick-Deetjen J, et al. In vitro formation of $\mathrm{N} \varepsilon$-(carboxymethyl) lysine and imidazolones under conditions similar to continuous ambulatory peritoneal dialysis (CAPD). Biochemistry and Biophysic Research Communication (2001), 280, 1408-14.

Toshio M, Yasuhiko U, Katsunori H, Masaomi N, Shuichi T, van Ypersele de Strihou $\mathrm{C}$ and Kiyoshi K. Renal catabolism of advanced glycation end products: The fate of pentosidine. Kidney International (1998), 53:2, 416-422.

Tsujii M, DuBois RN. Alterations in cellular adhesion and apoptosis in epithelial cells overexpressing prostaglandin endoperoxide synthase 2. Cell (1995), $83: 3,493-501$.

Ulrich P, Cerami A. (2001). Protein glycation, diabeest and aging. Recent Progress in Hormone Research, 56, 1-21.

Vander JDL, Hunsaker LA. Methylglyoxal metabolism and diabetic complications: roles of aldose reductase, glyoxalase-I, betaine aldehyde dehydrogenase, and 2-oxoaldehyde dehydrogenase. Chemistry and Biology Interaction (2003), 143-144.

Verzijl N, DeGroot J, Ben ZC, et al. Crosslinking by advanced glycation end products increases the stiffness of the collagen network in human articular cartilage: a possible mechanism through which age is a risk factor for osteoarthritis. Arthritis Rheumatology (2002), 46:1, 114-23.

Walle T. Methylation of dietary flavones greatly improves their hepatic metabolic stability and intestinal absorption. Molecular Pharmacology (2007), 4:6, 826832.

Wang L, Feng J, Chen X, Guo W, Du Y, Wang Y. Myricetin enhance chemosensitivity of 5-fluorouracil on esophageal carcinoma in vitro and in vivo. Cancer Cell International (2014), 14:71, 2-8.

Wang L, Tu Y, Lian TW, Hung JT, Yen JH, Wu MJ. Distinctive antioxidant and antiinflammatory effects of flavonols. Journal of Agriculture and Food Chemistry (2006), 54, 9798-9804.

Wells-Knecht MC, Thorpe SR, and Baynes JW. Pathways of formation of glycoxidation products during glycation of collagen. Biochemistry (1995), 34, 15134-15141.

Williams RJ, Spencer JP, Rice-Evans C. Flavonoids: antioxidants or signalling molecules? Free Radical Biology and Medicine (2004), 36:7, 838-849.

Yoshikazu Y, Ryo M, Yoko T, Hozumi T, et al. Anti-Glycation Effect of Mixed Herbal Extract in Individuals with Pre-Diabetes Mellitus: A Double-Blind, Placebo-Controlled, Parallel Group Study. Anti-Aging Medicine (2010), 7:5, 26-35. 